\title{
Effect of Massachusetts healthcare reform on racial and ethnic disparities in admissions to hospital for ambulatory care sensitive conditions: retrospective analysis of hospital episode statistics
}

\author{
Danny McCormick, ${ }^{1}$ Amresh D Hanchate, ${ }^{2,3}$ Karen E Lasser, ${ }^{3}$ Meredith G Manze, ${ }^{3}$ Mengyun Lin, ${ }^{3}$ \\ Chieh Chu, ${ }^{3}$ Nancy R Kressin ${ }^{2,3}$
}

${ }^{1}$ Harvard Medical School,

Department of Medicine,

Cambridge Health Alliance,

1493 Cambridge, MA 02139 ,

USA

2Veterans Affairs Boston

Healthcare System, Boston, MA 02130, USA

${ }^{3}$ Section of General Internal Medicine, Boston University

School of Medicine, Boston, MA 02118, USA

Correspondence to:

D McCormick danny

mccormick@hms.harvard.edu

Additional material is published

online only. To view please visit

the journal online (http://

dx.doi.org/10.1136/BMJ.h1480)

Cite this as: $B M J$ 2015;350:h1480 doi: 10.1136/bmj.h1480

Accepted: 05 March 2015

\section{ABSTRACT}

OBJECTIVES

To examine the impact of Massachusetts healthcare reform on changes in rates of admission to hospital for ambulatory care sensitive conditions (ACSCS), which are potentially preventable with good access to outpatient medical care, and racial and ethnic disparities in such rates, using complete inpatient discharge data (hospital episode statistics) from Massachusetts and three control states.

\section{DESIGN}

Difference in differences analysis to identify the change, overall and according to race/ethnicity, adjusted for secular changes unrelated to reform.

SETTING

Hospitals in Massachusetts, New York, New Jersey, and Pennsylvania, United States.

\section{PARTICIPANTS}

Adults aged 18-64 (those most likely to have been affected by the reform) admitted for any of 12 ACSCs in the 21 months before and after the period during which reform was implemented (July 2006 to December 2007).

\section{MAIN OUTCOME MEASURES}

Admission rates for a composite of all 12 ACSCs, and subgroup composites of acute and chronic ACSCs.

RESULTS

After adjustment for potential confounders, including age, race and ethnicity, sex, and county income, unemployment rate and physician supply, we found no evidence of a change in the admission rate for overall composite ACSC $(1.2 \%, 95 \%$ confidence interval $-1.6 \%$ to $4.1 \%$ ) or for subgroup composites of acute and

\section{WHAT IS ALREADY KNOWN ON THIS TOPIC}

Massachusetts healthcare reform increased the proportion of the state's residents who have health insurance, particularly among racial and ethnic minorities

Changes in rates of preventable admissions to hospital can reflect changes in access to outpatient medical care

A prior study examining the impact of the reform on preventable admissions yielded mixed results but had some methodological limitations

\section{WHAT THIS STUDY ADDS}

The Massachusetts health reform alone seems insufficient to improve populationwide preventable admissions or in pre-existing racial and ethnic disparities in such admissions

To reduce preventable admissions and disparities in preventable admissions, states such as Massachusetts need to go beyond simply expanding insurance coverage

chronic ACSCs. Nor did we find a change in disparities in admission rates between black and white people $(-1.9 \%,-8.5 \%$ to $5.1 \%)$ or white and Hispanic people (2.0\%, $-7.5 \%$ to $12.4 \%)$ for overall composite ACSC that existed in Massachusetts before reform. In analyses limited to Massachusetts only, we found no evidence of a change in admission rate for overall composite ACSC between counties with higher and lower rates of uninsurance at baseline $(1.4 \%,-2.3 \%$ to $5.3 \%)$.

\section{CONCLUSIONS}

Massachusetts reform was not associated with significantly lower overall or racial and ethnic disparities in rates of admission to hospital for ACSCs. In the US, and Massachusetts in particular, additional efforts might be needed to improve access to outpatient care and reduce preventable admissions.

\section{Introduction}

The United States has been atypical among industrialized countries in lacking a universal healthcare coverage system. Financial barriers to care, particularly for low income and uninsured people and racial and ethnic minorities, have been substantially higher in the US than in other wealthy countries. ${ }^{1}$ The landmark Patient Protection and Affordable Care Act (ACA) is a policy intervention designed to improve access to medical care through the largest expansion of insurance to low income people in US history; once fully implemented it is expected to provide coverage to 30 million previously uninsured people. ${ }^{2}$ The extent to which the act will be able to reduce barriers to accessing care and narrow racial and ethnic disparities in access is uncertain. The major coverage provisions in the act have been in place since January of 2014, but the effects of reform might not be realized early on. In 2006, the state of Massachusetts enacted a healthcare reform law that served as the template for the ACA. The Massachusetts reform provides an opportunity to examine the impact of a similar but more mature reform on access to care several years before data from the ACA will be available; it could provide lessons for ongoing reform implementation in the US and other countries that might contemplate analogous reforms.

The Massachusetts reform was designed to achieve "near universal" coverage, to improve access to care, and to decrease racial and ethnic disparities in both coverage and access ${ }^{34}$ that are well documented within the US healthcare system. ${ }^{5}$ In addition to extending coverage to the lowest income individuals-disproportionately comprising racial and ethnic minorities-the Massachusetts reform made reducing disparities an 
explicit goal. ${ }^{6}$ It also established a Health Disparities Council tasked with monitoring and making recommendations regarding racial and ethnic disparities in access to high quality care and health outcomes. ${ }^{7}$ According to data from the US Census Bureau, the percentage of uninsured non-elderly Massachusetts residents fell from about $12 \%$ in the period before reform (2004-06) to about 6\% in the period after reform (2008-09), ${ }^{8}$ with larger declines among racial and ethnic minorities and lower income individuals. ${ }^{9}$ Prior studies on the impact of this expansion on access to care have predominantly come from population based survey data, with most showing improvements in access to outpatient care such as inability to see a physician because of $\operatorname{cost}^{810-12}$ and receipt of some outpatient services, ${ }^{813} 14$ but little evidence of improvement in disparities after reform. ${ }^{11} 121415$ Yet studies based on survey data, however well conducted, rely on self report from respondents and are therefore potentially subject to cognitive, non-response, ${ }^{16}$ and other biases. Few studies have used objective data to examine utilization of care ${ }^{817-19}$ or clinical outcomes, ${ }^{2021}$ and only one examined a well established measure of access to outpatient care-rates of admission to hospital for ambulatory care sensitive conditions (ACSCs), ${ }^{8}$ conditions that are potentially preventable with good access to outpatient care. ${ }^{22} 23$ That single study had mixed results overall: no change was noted in the number of admissions for ACSCs in the primary analysis but after adjustment for measures of inpatient severity of illness, a 2.7 percentage point decline was noted. ${ }^{8}$ That study, however, examined a only fraction (20\%) of admissions in Massachusetts that occurred in only a subset of Massachusetts hospitals (48/70), potentially leading to both non-representativeness of the study sample and selection bias if insurance obtained under the reform led to a change in hospitals to which patients were admitted. In addition, that study did not examine racial and ethnic disparities in preventable admissions.

The Massachusetts health reform law expanded insurance coverage in three ways. First, it included an "individual mandate" that requires most adults in Massachusetts who can afford health insurance to have coverage or pay a tax penalty of up to $\$ 1272$ ( $£ 867$, $€ 1200$ ) a year (in 2013), ${ }^{24}$ depending on an individual's income, age, and family size. Second, the reform expanded publicly sponsored coverage through an extension of Medicaid (health insurance for Massachusetts residents with the lowest income) to previously ineligible residents, and the creation of Commonwealth Care, a publicly subsidized plan for residents with incomes below $300 \%$ of the US federal poverty level (\$23550 (£16050, €22171) a year for a family of four in 2013). ${ }^{25}$ Finally, the law created a health insurance exchange (the Massachusetts Health Connector) ${ }^{26}$ offering both subsidized plans (Commonwealth Care) and unsubsidized private plans (Commonwealth Choice) at a lower cost than was available before the reform. All health insurance products available through the Connector were required to offer benefit packages that met standards for "minimal creditable coverage" 27 and included preventive and primary care, emergency services, hospital stays, outpatient services, prescription drugs, and mental health services. Patterned closely on the Massachusetts reform, the ACA also includes an individual mandate, a Medicaid expansion, and publicly subsidized plans available for purchase through state based health benefit exchanges for those who do not qualify for Medicaid. ${ }^{28}$ The ACA requires that health insurance covers a range of services comparable with those covered by Massachusetts reform ${ }^{29}$ but offers subsidized plans for those with incomes up to $400 \%$ of the federal poverty levels rather than up to $300 \%$ under the Massachusetts reform.

We hypothesized that, after reform, expanded coverage would enable better access to outpatient care and as a result that preventable admissions to hospital would decline. Understanding whether this occurred overall and for racial and ethnic minorities could help inform ACA implementation; it could also hold insights for other countries that might consider moving toward a mixed healthcare financing model built on employer based private insurance with publicly subsidized insurance for the poor and a tax penalty enforced mandate to obtain coverage. To examine changes in access using objective data and to overcome potential limitations of prior studies, we assessed the impact of Massachusetts healthcare reform on rates of preventable admissions (those for ACSCs) using complete admission data. We used a quasi-experimental design to compare longitudinal changes (from before to after reform) in hospital admission rates for ACSCs in Massachusetts with concurrent changes in three control states not undergoing healthcare reform. We examined these ACSC changes for the Massachusetts population as a whole as well as among racial and ethnic subgroups. Finally, we evaluated whether the Massachusetts insurance expansion had differential effects related to the geographically varying baseline uninsurance rates within Massachusetts.

\section{Methods}

\section{General approach}

Comprehensive state-wide data on objective measures of access to outpatient medical care are not available in Massachusetts for the time periods just before and after reform. As comprehensive statewide data are available on all admissions to hospital, we examined changes in admissions rates for ACSCs, ${ }^{22} 23$ a well validated and widely used method to indirectly evaluate changes in access to outpatient care, particularly in relation to health insurance ${ }^{30-33}$ and racial and ethnic disparities. $^{34-37}$ The Agency for Healthcare Research and Quality (AHRQ) has defined and the National Quality Forum has endorsed a set of evidence based ACSCs to be used for this purpose, ${ }^{38}$ which we use here.

\section{Data sources and population}

We obtained patient level data on all hospital admissions to non-federal acute care hospitals in Massachusetts and three control states (New York (NY), New Jersey (NJ), and Pennsylvania (PA)) in 2004-10, 
obtained directly from the relevant state agency. These data include information on patient age, race, and ethnicity, sex, insurance type, diagnosis (ICD-9 (international classification of diseases, ninth edition) diagnostic codes), zip code, and dates of hospital admission. We linked zip code to data from the US Census Bureau ${ }^{39}$ to assess community characteristics and obtained county level population estimates according to age, sex, race and ethnicity, and zip code median income. The Area Resource File ${ }^{40}$ was used to obtain data on county unemployment rates and Health Professions Shortage Area (HPSA) designation, ${ }^{41}$ an indicator of county level supply of primary care physicians. Many of these variables are assigned at the county level as this is the only level that has annual denominators and because variables from some sources are available only at the county level.

To compare ACSC admission rates in counties with the highest baseline uninsurance rate (greatest potential for insurance gains after reform) with those with the lowest baseline uninsurance rates (lowest potential for insurance gains after reform), we obtained county level insurance rates from the US Census Bureau's Small Area Health Insurance Estimates (SAHIE). ${ }^{42}$

We included patients with an admission for any one of 12 adult ACSCs as the admitting diagnosis, identified using the AHRQ's Prevention Quality Indicators criteria $^{43}$ and who were aged 18-64. Nearly all US residents aged $\geq 65$ are and were, before the reform, covered by government insurance (Medicare).

\section{Study variables}

Our outcomes were admission rates for three composite measures of ACSCs defined by AHRQ: acute composite ACSCs (dehydration, urinary tract infection, and bacterial pneumonia), chronic composite ACSCs (short term and long term complications of diabetes, chronic

Ambulatory care sensitive conditions defined by Agency for Healthcare Research and Quality (AHRQ) prevention quality indicators (PQIs)

\section{Individual PQIs}

PQI 01 Diabetes short term complications admission rate

PQI 02 Perforated appendix admission rate (excluded)

$\mathrm{PQI} 03$ Diabetes long term complications admission rate

PQI 05 Chronic obstructive pulmonary disease or asthma in older adults admission rate PQI 07 Hypertension admission rate

$\mathrm{PQI} 08$ Congestive heart failure (CHF) admission rate

PQI 09 Low birth weight rate (excluded)

PQI 10 Dehydration admission rate

PQI 11 Bacterial pneumonia admission rate

$\mathrm{PQI} 12$ Urinary tract infection admission rate

PQI 13 Angina without procedure admission rate

PQI 14 Uncontrolled diabetes admission rate

PQI 15 Asthma in younger adults admission rate (excluded)

PQI 16 Rate of lower extremity amputation among patients with diabetes

\section{Composite PQIs}

PQI 90 Overall composite (includes 01, 03, 05, 07, 08, 10, 11, 12, 13, 14, 15, and 16)

PQI 91 Acute composite (includes 10, 11, and 12)

PQI 92 Chronic composite (includes 01, 03, 05, 07, 08, 13, 14, 15, and 16) obstructive lung disease, hypertension, heart failure, and angina) and overall composite ACSCs (acute and chronic measures combined). The box lists all individual and composite ACSC definitions. Admission rates were calculated per 100000 population per year and per quarter in the county of patient residence, overall and for racial and ethnic subgroups.

The primary independent variables were time (whether the admission occurred in the period before or after reform), state (Massachusetts $v$ control states), and the interaction between these two variables (to obtain an estimate of the difference in differences of the net percentage change-that is, the excess change after reform in Massachusetts over that in the control states). Implementation of reform in Massachusetts began on 1 July 2006 with Medicaid expansion to cover eligible low income individuals and ended with a tax penalty enforced mandate to acquire insurance coverage from 1 January 2008.44 Thus, we considered the period before reform to be the 21 months from 1 October 2004 to 30 June 2006 and the period after reform to be the 21 months from 1 January 2008 to 30 September 2009. This definition of the reform intervals, used in prior studies of the Massachusetts reform, ${ }^{17} 45$ balances the benefits of a large enough window of observation to establish ACSC admission levels before and after, an adequate sample size, and avoidance of time periods more distantly removed from the reform in which ACSC admission rates could be influenced by factors unrelated to the reform (such as substantial decline in US healthcare expenditures accelerating in 2010). ${ }^{46}$

Covariates included race and ethnicity, categorized as Hispanic, non-Hispanic white, non-Hispanic black, and "other"; age, categorized as 18-39, 40-49, 50-59, and 60-64; sex; quarter of the year; time period (before/after reform); and intervention state (Massachusetts/controls). County level variables were median income (thirds), median unemployment rate (thirds), and HPSA designation (no, partial, or whole physician shortage area); in addition, we included county indicators to capture time invariant unobserved area level effects.

\section{Analytic data structure}

To estimate hospital admission rates before and after reform, we produced an analytic dataset by stratifying the state population into cohorts according to race and ethnicity, age, sex, county, time period (before $v$ after reform), and quarter of the year. We stratified population at the county level to adjust for geographic heterogeneity (within states) in factors determining admission rates as this is the finest sub-state level for which annual census population counts were available. ${ }^{39}$ With each county stratified into cohorts, we had 6272 observations for the periods before and after reform in Massachusetts combined and 67200 observations for same periods in control states.

\section{Analysis}

We used a naturally occurring quasi-experimental design, treating Massachusetts as the exposed group 
and states without health reform as the control group. First, to represent the data visually, we calculated admission rates over time as the moving averages of four quarters (each quarter averaged with the three quarter that preceded it) to smooth out seasonal variation. In a separate analysis, we then estimated admission rates before and after reform for the acute, chronic, and overall composite measures. We adjusted these rates for compositional differences in sex and age by direct standardization. ${ }^{47}$ We then estimated the unadjusted percentage change in admission rates after reform by subtracting the change in rates among control states from the change observed in Massachusetts. We then used a difference in differences approach ${ }^{48}$ to estimate the adjusted percentage change in ACSC admission rates in Massachusetts by accounting for contemporaneous changes in admission rates in control states and all other covariates in multivariate models. This method allows for comparison of two groups (exposed and unexposed) over time and, when used in a regression framework, can adjust for confounders while controlling for unobserved individual differences and for common trends. ${ }^{49}$ We used Poisson regression models with ACSC admission count as the outcome measure and census population count as the population at risk. We adjusted persistent (time invariant) differences by geography with county level fixed effects and for secular temporal fluctuations with a dummy indicator variable for quarter. We also obtained robust standard error estimates adjusted for county level clustering. ${ }^{50}$

In addition, to examine changes before and after reform in pre-existing racial and ethnic disparities in ACSCs, we conducted an analysis using the same modeling approach and covariates to estimate whether admission rates for ACSCs had changed for black people or Hispanic people relative to white residents in Massachusetts for each composite outcome measure (analogous to a "difference in difference in differences" analysis with white people taken as the "control group").

We also compared changes in ACSC rates in the seven counties that had the lowest rates of uninsurance with the seven counties that had the highest rates before reform and thus potentials for gains in insurance as a result of the reform. As expected, when we grouped by actual gains in insurance coverage after reform, this resulted in the same two groups. We used a difference in differences approach employing Poisson regression models identical to those described above except that rather than conducting comparisons with control states, we compared two groups of counties with the highest and lowest potential for gains in insurance within Massachusetts.

We also performed multiple sensitivity analyses to test the robustness of our preferred baseline modeling approach and time period of observation. Specifically, we re-estimated the baseline model (Poisson regression) using an additional year of data in the period after reform; only propensity score matched counties in control states; bootstrap method to calculate standard errors (in fixed and, separately, random effects models); and negative binomial and linear regression models. We also estimated outcomes using interrupted time series ${ }^{51}$ models with all the covariates in the baseline model (see details of modeling and results in appendix 1). Also, to assess the robustness of our results to selection of particular control states, we re-estimated models excluding one control state at a time to ensure that no single comparator state was driving the results. Lastly, we conducted analyses to test whether trends in admission rates before reform differed between Massachusetts and control states (appendix 1).

Significance was assessed at $\mathrm{P}<0.05$ (two tailed), and all estimations were performed with Stata version 13.1 and SAS software, version 9.2.

\section{Results}

\section{Patient sample}

We studied 893924 admissions to hospital for ACSCs, 102541 in Massachusetts and 791383 in control states. Before reform, patients admitted in control states were more likely to be black or "other" race or ethnicity and to reside in counties with lower median incomes (table 1).

\section{Rates of preventable admission}

The figure shows plots of age and sex standardized rates and moving four quarter averages for the overall composite ACSC hospital admission rate, smoothed for seasonal variation. These plots shows that rates were higher in control states than in Massachusetts but that little change occurred over the entire study period for either.

Age and sex standardized rates for the overall composite ACSC measure declined slightly in Massachusetts $(-2.1 \%)$ but did so to a greater degree in control states (-3.5\%; table 2). Difference in differences analyses for the overall composite measure found no evidence of a significant change in hospital admission rates in Massachusetts versus those in control states in either unadjusted analyses or those adjusted for changes in hospital admission rates in control states and multiple individual and county level baseline patient characteristics (1.2\%, $95 \%$ confidence interval -1.6 to 4.1$)$. We obtained similar findings for both the acute composite and chronic composite ACSC measures.

\section{Rates of preventable admissions by race and ethnicity}

Point estimates for hospital admission rates/100 000 before reform for the overall composite ACSC measure varied by race and ethnicity in both Massachusetts and control states. For example, in Massachusetts, the admission rate/100 000 before reform was 667 for white people, 1258 for Hispanic people, and 1713 for black people (table 3 ). In adjusted difference in differences analyses we found no changes in admission rates for any race or ethnicity for the three ACSC composite measures except for an increase in admission rates for chronic composite conditions for white people. In multivariate analyses we also found no evidence of a change in disparities between white and black people ( $-1.9 \%, 95 \%$ confidence interval $-8.5 \%$ to $5.1 \%$ ) or white 


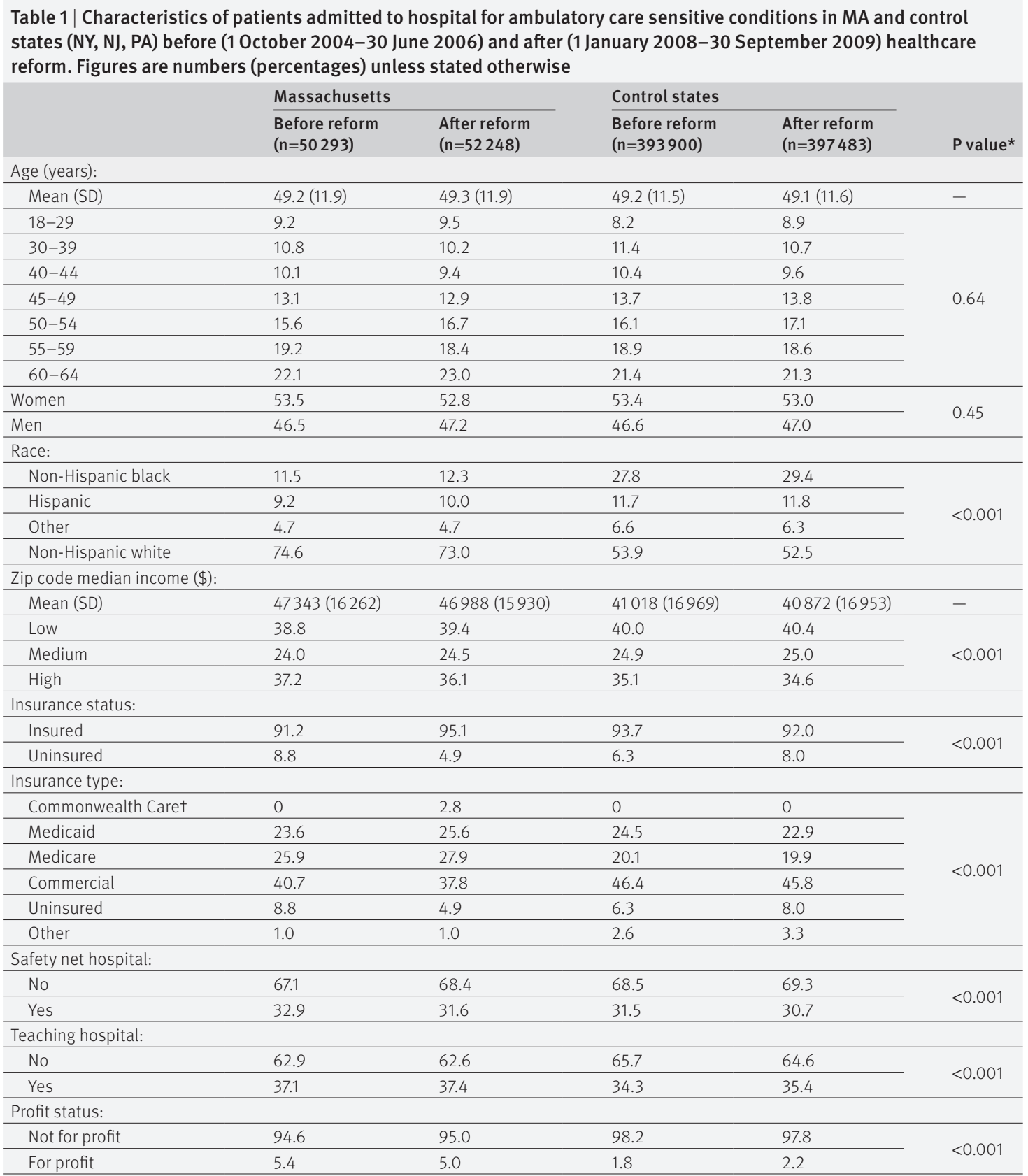

*For comparison of MA before reform with control states before reform

tCommonwealth Care is publicly subsidized private insurance for people with low incomes created under Massachusetts reform.

and Hispanic people $(2.0 \%,-7.5 \%$ to $112.4 \%)$ in the overall composite ACSC admission rate after reform. Similarly, for the acute and chronic measures, we found no evidence of significant changes in disparities between white and black people and white and Hispanic people that had existed before reform in Massachusetts.

The overall composite rate of preventable admissions before reform was higher for older patients, female patients, those with lower incomes, and those living in counties with higher unemployment levels (data not shown). We found no significant changes in admission rates for any subgroup of patients (data not shown).

We also found no evidence that the overall composite ACSC hospitalization rate in Massachusetts counties with the greatest potential (and actual) gains in coverage was different from the rate in counties with the lowest potential (and actual) gains, in multivariate analyses (adjusted \% change 1.5\%, 95\% confidence interval $-2.2 \%$ to $5.2 \%$; where a point estimate above 1 indicates a higher admission rate after reform in Massachusetts counties with greater potential gains in insurance coverage; table 4). Again, similar results were obtained for the acute and chronic measures.

Several sensitivity analyses including use of propensity score matched control counties and alternative model specifications (using bootstrap method to calculate standard errors with fixed effects and alternately, random effects specifications, negative binomial, linear, interrupted time series) produced similar results 

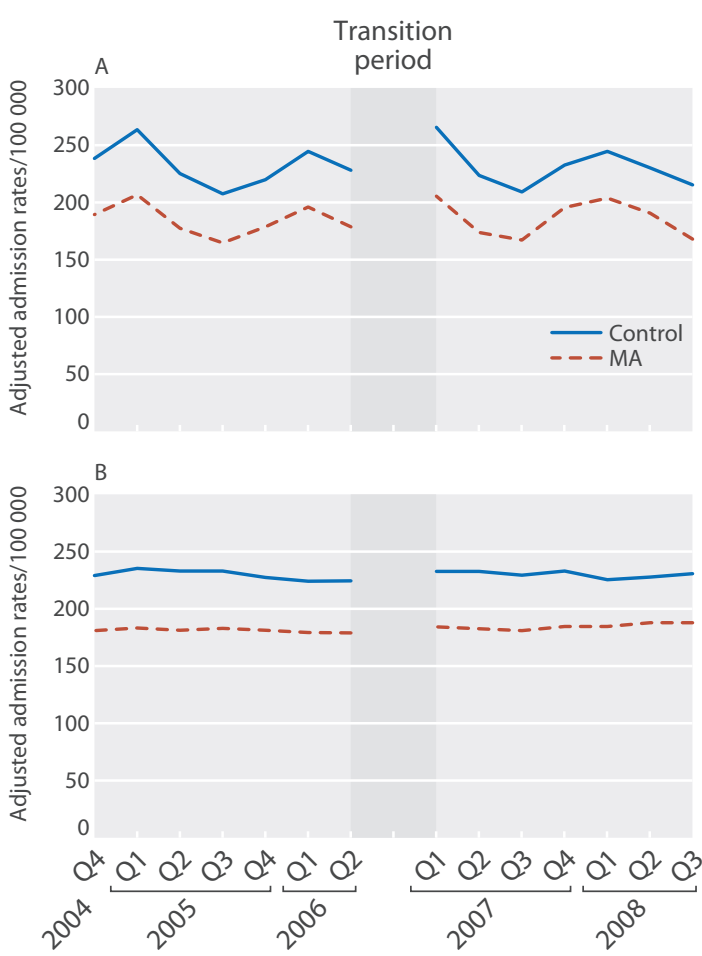

Time trends in hospital admission rates $/ 100000$ population for composite of 12 ambulatory care sensitive conditions in MA and control states (NY, NJ, PA) from periods before and after reform standardized for age and sex and as four quarter rolling averages to smooth seasonal variation. Transition period represents time period during which reform was being implemented

(see table A and B in appendix 2) for overall ACSC admission rates and for changes in racial and ethnic disparities in ACSC admission rates. Exclusion of each control state individually from the analysis also did not change our results. Addition of extra months of data in the period after reform resulted in an increase in ACSC admissions for the overall and chronic ACSCs but no changes in the results for acute ACSCs or racial and ethnic disparities in any ACSC measure. We found no evidence that trends in Massachusetts before reform diverged from those in control states (table C, appendix 2).

\section{Discussion}

Admission rates for ambulatory care sensitive conditions (ACSCs) are indicative of access to outpatient care. 22 23 30-33 3852 Using complete inpatient hospital records data we found no evidence that hospital admission rates for ACSCs changed in Massachusetts after implementation of healthcare reform compared with rates in states that did not undergo healthcare reform. We also found no evidence that admission rates for ACSCs declined to a greater degree in counties in Massachusetts with the highest baseline uninsurance rates (and largest gains in insurance after reform) compared with those with the lowest baseline uninsurance rates (and smallest gains after reform). Lastly, we failed to find evidence of a significant narrowing of pre-existing racial and ethnic disparities in this outcome (between white and black people or between white and Hispanic people) in comparison with control states. Most, but not all, prior studies have shown improvements in multiple measures of access to care with less evidence that racial and ethnic disparities improved. In contrast, using the specific hospital related metric of preventable admissions we could not find significant improvements in access or disparities in access to outpatient care after implementation of Massachusetts healthcare reform.

\section{Limitations and strengths}

Several limitations of this study should be noted. First, while assessment of rates of hospital admissions for ACSCs is a well validated method of assessing changes in access to care, it does so indirectly; we could not assess actual outpatient utilization or patient experiences of access to care. Second, control states in our analyses had lower baseline insurance rates, larger minority populations, and a lower median income than in Massachusetts. While we controlled for multiple variables by which Massachusetts and control states differed, including population demographics, measures of economic conditions (county level income and unemployment rates), and local physician supply, we could not control for other potential unmeasured factors such as local "medical culture" that could have influenced our results.

Our sensitivity analysis using only propensity score matched counties provides some additional reassurance that selected control states were appropriate. In addition, to assess the impact of the reform on racial and ethnic disparities in access, a key objective of our study, it was necessary to use comparator states that have sizable minority populations. Hence, we selected three control states in the northeast US, identical to

Table 2 | Changes in rates of preventable hospital admissions* per 100000 residents/year in Massachusetts and control states (NY, NJ, PA) before (1 October 2004-30 June 2006) and after (1 January 2008-30 September 2009) healthcare reform

\begin{tabular}{|c|c|c|c|c|c|c|c|c|}
\hline \multirow[b]{2}{*}{ ACSC measuret } & \multicolumn{3}{|c|}{ Massachusetts } & \multicolumn{3}{|c|}{ Control states } & \multicolumn{2}{|c|}{ Differences in differences estimates } \\
\hline & Before & After & $\%$ change & Before & After & $\%$ change & Unadjusted $\%$ change & Adjusted \% change $(95 \% \mathrm{Cl})$ \\
\hline Overall composite & 745 & 730 & -2.1 & 945 & 912 & -3.5 & 1.4 & $1.2(-1.6$ to 4.1$)$ \\
\hline Acute composite & 300 & 279 & -7.0 & 308 & 292 & -5.1 & -1.9 & $-2.0(-5.2$ to 1.3$)$ \\
\hline Chronic composite & 445 & 451 & 1.3 & 637 & 620 & -2.7 & 4.0 & $3.7(-0.04$ to 7.6$)$ \\
\hline
\end{tabular}

*Adjusted for age and sex with method of direct standardization.

tAmbulatory care sensitive conditions (ACSCS) are set of conditions, defined by Agency for Health Care Research and Quality, for which access to outpatient care should reduce risk of admission. Acute composite includes dehydration, urinary tract infection, and bacterial pneumonia. Chronic composite includes diabetes, complications from diabetes, chronic obstructive pulmonary disease, hypertension, heart failure, and angina. Overall composite includes all individual ACSCs in acute and chronic composite measures.

$\ddagger$ btained from Poisson regression models adjusted for sex, age, race/ethnicity, county income level, county unemployment rate, quarter, and Health Professions Shortage Area designation. 
Table 3 | Changes in rates of preventable hospital admissions per 100000 residents/year in Massachusetts and control states (NY, NJ, PA) before (1 October 2004-30 June 2006) and after (1 January 2008-30 September 2009) healthcare reform according to race and ethnicity

\begin{tabular}{|c|c|c|c|c|c|c|c|c|c|}
\hline \multirow[b]{2}{*}{ ASCS measures } & \multicolumn{3}{|c|}{ Massachusetts } & \multicolumn{3}{|c|}{ Control states } & \multicolumn{2}{|c|}{ Differences in differences estimates } & \multirow{2}{*}{$\begin{array}{l}\text { Adjusted estimated \% } \\
\text { change }(95 \% \mathrm{Cl}) \dagger\end{array}$} \\
\hline & Before & After & $\%$ change & Before & After & $\%$ change & Unadjusted & Adjusted $(95 \% \mathrm{CI})^{\star}$ & \\
\hline \multicolumn{10}{|c|}{ Overall composite } \\
\hline White & 667 & 647 & -3.0 & 716 & 680 & -5.1 & 2.1 & $2.1(-0.8$ to 5.0$)$ & Ref \\
\hline Black & 1713 & 1744 & 1.8 & 2188 & 2240 & 2.4 & -0.6 & $-0.5(-6.0$ to 5.3$)$ & $-1.9(-8.5$ to 5.1$)$ \\
\hline Hispanic & 1258 & 1203 & -4.4 & 1126 & 1024 & -9.1 & 4.7 & $1.6(-3.9$ to 5.5$)$ & $2.0(-7.5$ to 12.4$)$ \\
\hline \multicolumn{10}{|l|}{ Acute composite } \\
\hline White & 285 & 263 & -7.5 & 277 & 262 & -5.6 & -1.9 & $-1.8(-5.2$ to 1.7$)$ & Ref \\
\hline Black & 496 & 470 & -5.3 & 482 & 476 & -1.2 & -4.0 & $-4.0(-12.2$ to 5.1$)$ & $-1.4(-12.7$ to 11.4$)$ \\
\hline Hispanic & 393 & 362 & -7.8 & 297 & 276 & -7.3 & -0.5 & $-1.2(-9.9$ to 8.3$)$ & $2.0(-10.3$ to 15.7$)$ \\
\hline \multicolumn{10}{|c|}{ Chronic composite } \\
\hline White & 383 & 384 & 0.3 & 440 & 419 & -4.7 & 5.0 & $5.0(1.6$ to 8.6$)$ & Ref \\
\hline Black & 1217 & 1274 & 4.7 & 1706 & 1764 & 3.4 & 1.3 & $1.3(-4.9$ to 7.9$)$ & $-3.1(-9.4$ to 3.7$)$ \\
\hline Hispanic & 865 & 840 & -2.8 & 829 & 748 & -9.7 & 6.9 & $2.9(-3.4$ to 9.5$)$ & $-0.7(-9.6$ to 12.2$)$ \\
\hline
\end{tabular}

*Adjusted difference in differences estimates and $95 \% \mathrm{Cl}$ obtained from Poisson regression models adjusted for sex, age, race/ethnicity, county income level, county unemployment rate, quarter, and Health Professions Shortage Area designation.

tFor change in racial/ethnic disparities in MA $v$ controls. Expresses change in disparities after reform between black and white people and between Hispanic and white people in ACSC (preventable hospitalization) rates after adjustment for changes in control states.

Table 4 | Changes in rates of preventable hospital admissions per 100000 residents/year in Massachusetts counties with highest and lowest potential insurance coverage gains after healthcare reform*

\begin{tabular}{|c|c|c|c|c|c|c|c|}
\hline \multirow[b]{3}{*}{ ASCS measures } & \multicolumn{6}{|c|}{ Potential insurance coverage gains } & \multirow{3}{*}{$\begin{array}{l}\text { Adjusted } \% \text { change } \\
\text { in difference in } \\
\text { differences } \\
\text { estimates }(95 \% \mathrm{Cl}) \dagger\end{array}$} \\
\hline & \multicolumn{3}{|l|}{ Highest } & \multicolumn{3}{|l|}{ Lowest } & \\
\hline & Before & After & $\%$ change & Before & After & $\%$ change & \\
\hline Overall composite & 711.7 & 696.5 & $-2.1 \%$ & 788.3 & 773.5 & $-1.9 \%$ & $1.4 \%(-2.3 \%$ to $5.3 \%)$ \\
\hline Acute composite & 282.0 & 265.3 & $-5.9 \%$ & 323.5 & 297.0 & $-8.2 \%$ & $3.3 \%(-1.8 \%$ to $8.5 \%)$ \\
\hline Chronic composite & 429.7 & 431.2 & $0.3 \%$ & 464.8 & 476.5 & $2.5 \%$ & $0.2 \%(-4.1 \%$ to $4.5 \%$ \\
\hline \multicolumn{8}{|c|}{$\begin{array}{l}\text { *Data from study states and Small Area Health Insurance Estimates (SAHIE) produced by US Census Bureau. } \\
\text { Counties with highest potential (and actual) insurance coverage gains were those above median and counties } \\
\text { with lowest potential (and actual) gains were those below median for baseline uninsurance rates before reform, } \\
\text { according to SAHIE Estimates. } \\
\text { tExpresses change after reform in counties with highest insurance coverage gains compared with counties with } \\
\text { lowest gains in coverage after adjustment in Poisson regression models adjusted for sex, age, race/ethnicity, } \\
\text { county income level, county unemployment rate, quarter, and Health Professions Shortage Area designation. } \\
\text { Significant positive values indicate increase in admission rate in counties with highest potential coverage gains } \\
\text { and negative values indicate decrease in admission rate in counties with highest potential coverage gains. }\end{array}$} \\
\hline
\end{tabular}

control states used in prior work on Massachusetts health reform, ${ }^{13} 1753$ that balance geographic proximity to Massachusetts with adequacy of the size of minority populations. The fact that sequential individual elimination of each control state had no impact on the results suggests that our findings were not simply because of the particular control states selected. A third limitation is a potential lack of generalizability; incomes and the rate of insurance were higher and the proportion of racial and ethnic minorities was lower in Massachusetts before reform than in many other states. A higher rate of insurance (1.1 percentage points higher than the median US state rate ${ }^{8}$ ) could mean that there was less room for improvement than would be the case in some other states. The six percentage point gain in insurance after Massachusetts reform, however, is only slightly lower than the average expected gain in insurance of $7.1 \%$ nationally under the ACA. ${ }^{54}$ Massachusetts also has a larger ratio of physicians to residents than other states, which could suggest better access to care before and after reform, with uncertain effects on the magnitude of access improvement. Thus, our results might be generalizable only to states similar to Massachusetts.
A fourth limitation is that expanded access to insurance could increase access to inpatient care and drive up admission rates, offsetting any declines because of improved outpatient access. While this would be likely for some conditions such as discretionary surgical procedures, ${ }^{45}$ we studied only admissions for conditions that have been shown to decline when outpatient access to care improves. ${ }^{55}$ Fifth, most area level data in this study are at the county level and thus less granular than a smaller area unit such as a census block; however, no such publicly available data exists. Lastly, while we found no evidence of a change in ACSC admission rates or disparities therein, we cannot rule out meaningful reductions, particularly for racial and ethnic minorities. The lower 95\% confidence limit for our composite overall ACSC measure is compatible with an overall reduction of 1.6 percentage points, and reductions in disparities between black and white people and between Hispanic and white people of 8.5 and 7.5 percentage points, respectively, which would be substantial. Our preferred model specification, however, was conservative; multiple alternative modeling specifications tested in sensitivity analyses produced considerably narrower 95\% confidence intervals for all analyses.

Several strengths of our study should also be noted. First, we relied on an objectively measured outcome that was therefore not subject to potential biases from patient recall or cognitive factors that could have influenced patient responses in survey studies that comprise most of the evidence base on the impact of the Massachusetts reform on access to care. Second, our study did not rely on statistical sampling during the study period-we used every hospital admission occurring in Massachusetts and control states during this time. Therefore, concerns about potential non-representative sampling that can lead to poor generalizability do not apply. Third, our results were robust to numerous alternative modeling strategies and specifications. Lastly, our study is the first we are aware of to examine the impact of the reform on racial and ethnic disparities in preventable admissions. 


\section{Comparison with other studies}

Most of what is known about the Massachusetts reform's impact on access to care comes from population based surveys, which have found improvements in measures of access to care, such as having a personal physician (1.3-6.6 percentage point improvement), 81014 inability to see a physician because of cost (1.5-3.1 percentage point improvement), ${ }^{810-12}$ and out of pocket medical spending at $10 \%$ or more of family income (3.7 percentage point improvement). ${ }^{56}$ Some studies have also found increases in utilization of appropriate outpatient care such as receiving flu vaccine (1.6 to 3.0 percentage point improvement) $)^{813}$ and screening colonoscopy (5.5 percentage point improvement). ${ }^{14}$ For other services, such as cholesterol checks ${ }^{814}$ and cervical smear tests, ${ }^{11} 14$ evidence is conflicting, and for others, such as mammography, no improvements were found. ${ }^{11} 1457$

In contrast, most of the few of these studies that examined racial and ethnic disparities in access failed to find a narrowing after reform, similar to our results. One prior study found greater improvements in having a personal physician for Hispanic compared with white residents (although among individuals who speak only Spanish this outcome substantially worsened after reform), ${ }^{15}$ while two studies found no improvement in racial and ethnic disparities in this outcome. ${ }^{1214}$ Still other studies found no change in racial and ethnic disparities in being unable to see a physician because of $\operatorname{cost}^{111214}$ or receipt of preventive services. ${ }^{14}$ Self reported outcomes, however, are subject to potential biases that could have influenced survey responses. For example, it is possible that simply having insurance coverage provided a sense of wellbeing and security that positively influenced answers to subjective questions in the absence of objective changes in health or access to care, as was noted in a recent randomized expansion of Medicaid in the state of Oregon in the US. ${ }^{58} 59$ Even small effects from this could explain much of the effect sizes noted in these prior studies.

The few studies that used objective data to examine overall changes in access to care show a mixed picture. For example, emergency department use declined after reform according to one study ${ }^{60}$ but increased according to another. ${ }^{19}$ State-wide mortality seems to have declined in Massachusetts after reform, ${ }^{61}$ but among patients with hyperlipidemia, diabetes, and hypertension who gained insurance under the reform, objectively measured cholesterol, hemoglobin $\mathrm{A}_{\mathrm{c}}$, and blood pressure levels did not change. ${ }^{21}$ The only prior study of preventable admissions showed a decline in ACSC admission rates after reform only after adjustment for measures of severity of illness (predominantly the numbers of comorbidities and inpatient diagnoses). ${ }^{8}$ As its authors noted, however, incorporating diagnoses from administrative data in risk adjustments could introduce over-adjustment if the comorbid conditions are a product of the same access to care barriers that result in admissions for ACSCs. Adjustment for comorbidities could also lead to erroneous results if, for example, the average number of comorbidities increased after reform as a result of increased detection ${ }^{62}$ in even a single office based physician visit made possible by gaining insurance, or from more aggressive or complete inpatient coding to maximize hospital revenue (so called "upcoding") ${ }^{63}$ among Massachusetts hospitals, rather than as a result of a true increase in the prevalence of chronic conditions among inpatients after reform. Prior studies using objective data to examine changes after reform in disparities have found no improvement in disparities in hospital readmission rates ${ }^{17}$ and access to inpatient cardiovascular procedures, ${ }^{18}$ while access to inpatient surgical procedures did improve for minorities. ${ }^{45}$ Our study is the first to examine this question using preventable admissions as a measure of access to outpatient care.

\section{Conclusion and policy implications}

Why might Massachusetts health reform have failed to affect preventable admissions or narrow pre-existing racial and ethnic disparities in this outcome? First, although estimates vary somewhat, the absolute decline in the number of uninsured residents was about $6 \%$ of the non-elderly population; this still left $6 \%$ of the non-elderly population uninsured after full implementation of the reform ${ }^{8}$. While gains were larger for racial and ethnic minorities, so too was the proportion of uninsured after reform. Second, before reform, Massachusetts had a robust healthcare safety net system that provided free care to many of the uninsured, ${ }^{64}$ who were disproportionately from minority backgrounds, through the state's Uncompensated Care Pool program. Third, the public insurance (Medicaid) and publicly subsidized (Commonwealth Care) and unsubsidized (Commonwealth Choice) exchange based private insurance that residents received under the reform might not have provided optimal access to outpatient care because patients had to share costs ${ }^{65} 66$ or of because of low provider reimbursement. In 2009 the Massachusetts Medical Society found that only $60 \%$ of internist physicians in Massachusetts accepted Medicaid and 40\% accepted Commonwealth Care, ${ }^{67}$ and anecdotal evidence suggests that finding a physician after reform became more difficult. ${ }^{68}$ Lastly, there could have been insufficient capacity of outpatient primary care providers to fully accommodate the influx of newly insured residents, irrespective of insurance type. Recent data regarding this possibility are mixed. ${ }^{13} 69$

The persistence of racial and ethnic disparities despite increased insurance coverage has been shown in many other settings ${ }^{70} 71$ and in our study might be because of office based barriers faced by racial and ethnic minorities such as a lack of available interpreters ${ }^{72}$ or discrimination, ${ }^{5}$ persistent inability to afford care despite being insured because of cost sharing, ${ }^{73}$ or to the enduring independent effects of socioeconomic factors $^{74}$ that we were unable to account for in our analysis.

In addition to being a key measure of access, preventable admissions represent a clinical failure for patients and a needless expenditure of scarce healthcare resources. Our findings therefore have important policy implications. A large body of evidence suggests that insurance substantially improves access to care across 
many settings, medical conditions, and populations. ${ }^{75}$ In fact, recent US longitudinal studies provide strong evidence that acquiring public forms of insurance such as Medicaid and Medicare improves a broad array of health outcomes ${ }^{5876}$ including mortality ${ }^{61}$ The fact that we found no evidence that the Massachusetts reform diminished either preventable admissions or disparities in such admissions, suggests that particular features of the Massachusetts reform might need to be optimized to realize improvements in access to outpatient care that can prevent admissions. Although our results do not point to specific modifications, they might include continued expansion of insurance to the remaining uninsured, reduction in cost related barriers to outpatient care among those with insurance, and more comprehensive outreach efforts to the insured and uninsured to ensure adequate knowledge of the processes for applying for and effectively utilizing insurance, particularly among residents with limited proficiency in English language and low health literacy. Future studies will need to define which of these or other improvements will maximize outpatient access to care. While healthcare delivery systems vary substantially internationally, our results could provide insight into reforms of healthcare financing built on a mix of private and public funding and individual mandates that both wealthy and less wealthy countries could contemplate.

Contributors: All authors contributed to the data analysis and interpretation of the results, and reviewed and approved the final manuscript. DM had full access to all of the data in the study and takes responsibility for the integrity of the data and the accuracy of the data analysis. DM is guarantor.

Funding: This research was funded by US National Institutes of Health grants (1U01HL105342-01, NRK, principal investigator) and a grant from the Rx foundation. NRK is supported in part by a senior research career scientist award from the Department of Veterans Affairs, Health Services Research and Development Service (RCS 02-066-1). The views expressed in this article are those of the authors and do not necessarily represent the views of the National Institutes of Health, the Rx foundation, Boston University, or the Department of Veterans Affairs. The funders had no role in conducting the research or writing of the manuscript.

Competing interests: All authors have completed the ICMJE uniform disclosure form at www.icmje.org/coi_disclosure.pdf and declare: no support from any organisation for the submitted work; no financial relationships with any organisations that might have an interest in the submitted work in the previous three years; no other relationships or activities that could appear to have influenced the submitted work.

Ethical approval: This study was approved by the Boston University Medical Campus institutional review board.

Data sharing: Inpatient data files were restricted for this project and cannot be shared because of restrictions on use of data. Statistical code files are available from the corresponding author.

Transparency: DM (the manuscript's guarantor) affirms that the manuscript is an honest, accurate, and transparent account of the study being reported; that no important aspects of the study have been omitted; and that any discrepancies from the study as planned (and, if relevant, registered) have been explained.

This is an Open Access article distributed in accordance with the Creative Commons Attribution Non Commercial (CC BY-NC 4.0) license, which permits others to distribute, remix, adapt, build upon this work non-commercially, and license their derivative works on different terms, provided the original work is properly cited and the use is non-commercial. See: http://creativecommons.org/licenses/ by-nc/4.0\%

Davis K, Ballreich J. Equitable access to care-how the United States ranks internationally. N Engl / Med 2014;371:1567-70. 2 AHRQ. National Healthcare Disparities Report 2013. Agency for Healthcare Research and Quality, 2013.
3 189th General Court of the Commonwealth of Massachusetts. Chapter 58: An Act Providing Access to Affordable, Quality Accountable Health Care. www.malegislature.gov/Laws/SessionLaws/Acts/2006/Chapter58. 4 Long SK. On the road to universal coverage: impacts of reform in massachusetts at one year. Health Aff (Milwood) 2008;27:w270-84.

5 Institute of Medicine of the National Academies. Unequal treatment: confronting racial and ethnic disparities in health care. National Academy of Sciences 2003

6 187th General Court of the Commonwealth of Massachusetts. Massachusetts General Laws, chap. 6A, sec. 16L, Health Care Quality and Cost Council. https://malegislature.gov/Laws/SessionLaws/ Acts/2006/Chapter58.

7 187th General Court of the Commonwealth of Massachusetts. Massachusetts General Laws, chap. 6A, sec. 16K, Health Care Quality and Cost Council. https://malegislature.gov/Laws/SessionLaws/ Acts/2006/Chapter58

8 Kolstad JT, Kowalski AE. The Impact of health care reform on hospital and preventive care: evidence from Massachusetts. J Public Econ 2012;96:909-29.

9 Kolstad IT Kowalski AE The impact of health care reform on hospital and preventive care: evidence from Massachusetts. National Bureau of Economic Research, 2010. (Working Paper 16012).

10 Pande AH, Ross-Degnan D, Zaslavsky AM, et al. Effects of healthcare reforms on coverage, access, and disparities: quasi-experimental analysis of evidence from Massachusetts. Am J Prev Med 2011;41:1-8

11 Clark CR, Soukup J, Govindarajulu U, et al. Lack of access due to costs remains a problem for some in Massachusetts despite the state's health reforms. Health Aff (Milwood) 2011;30:247-55

12 Zhu J, Brawarsky P, Lipsitz S, et al. Massachusetts health reform and disparities in coverage, access and health status. J Gen Intern Med 2010;25:1356-62

13 Miller S. The effect of the Massachusetts reform on health care utilization. Inquiry 2012;49:317-26.

14 Van Der Wees PJ, Zaslavsky AM, Ayanian JZ. Improvements in health status after massachusetts health care reform. Milbank Quarterly 2013;91:663-89.

15 Maxwell J, Cortés D, Schneider K, et al. Massachusetts' health care reform increased access to care for Hispanics, but disparities remain. Health Aff (Milwood) 2011;30:1451-60.

16 Groves RM. Nonresponse rates and nonresponse bias in hosehold surveys. Public Opin Q 2006;70:646-75.

17 Lasser KE, Hanchate AD, McCormick D, et al. The effect of Massachusett health reform on 30 day hospital readmissions: retrospective analysis of hospital episode statistics. BM/ 2014:348:g2329.

18 Albert MA, Ayanian JZ, Silbaugh TS, et al. Early results of massachusetts healthcare reform on racial, ethnic, and socioeconomic disparities in cardiovascular care. Circulation 2014:129:2528-38.

19 Smulowitz PB, Lipton R, Wharam JF, et al. Emergency department utilization after the implementation of Massachusetts health reform. Ann Emerg Med 2011:58:225-34.

20 Sommers BD, Long SK, Baicker K. Changes in mortality after Massachusetts health care reform: a quasi-experimental study. Ann Intern Med 2014:160:585-93.

21 Stryjewski TP, Zhang F, Eliott D, et al. Effect of Massachusetts health reform on chronic disease outcomes. Health Serv Res 2014;49(suppl 2): 2086-103.

22 Bindman AB, Grumbach K, Osmond D, et al. Preventable hospitalizations and access to health care. JAMA 1995;274:305-11.

23 Ansari Z, Laditka JN, Laditka SB. Access to health care and hospitalization for ambulatory care sensitive conditions. Med Care Res Rev 2006;63:719-41.

24 Mass.gov. Health care reform: general information. www.mass.gov/ dor/individuals/taxpayerhelp-and-resources/health-care-reforminformation/general-information-for-individuals.html.

25 Office of the Asistant Secretary of Planning and Evaluation/US Department of Health and Human Services. Secondary 2013 poverty guidelines. http://aspe.hhs.gov/poverty/13poverty.cfm\#guidelines.

26 kff.org. State marketplace profiles: Massachusetts. http://kff.org/ health-reform/state-profile/state-exchange-profiles-massachusetts/.

27 Maconnector.org. Minimum creditable coverage. www. mahealthconnector.org/wp-content/uploads/rules-andregulations/956CMR5.00.pdf

28 kff.org. Summary of the affordable care act. kaiserfamilyfoundation. files.wordpress.com/2011/04/8061-021.pdf.

29 HealthCare.gov. Essential health benefits. www.healthcare.gov/ glossary/essential-healthbenefits/.

30 Bindman AB, Chattopadhyay A, Auerback GM. Interruptions in Medicaid coverage and risk for hospitalization for ambulatory care-sensitive conditions. Ann Intern Med 2008;149:854-60.

31 Bindman AB, Chattopadhyay A, Auerback GM. Medicaid re-enrollment policies and children's risk of hospitalizations for ambulatory care sensitive conditions. Med Care 2008;46:1049-54

32 Weissman JS, Gatsonis C, Epstein AM. Rates of avoidable hospitalization by insurance status in Massachusetts and Maryland. IAMA 1992:268:2388-94. 
33 Millett C, Chattopadhyay A, Bindman AB. Unhealthy competition: consequences of health plan choice in California Medicaid. Am J Pub Health 2010:100:2235-40.

34 Laditka JN, Laditka SB, Mastanduno MP. Hospital utilization fo ambulatory care sensitive conditions: health outcome disparities associated with race and ethnicity. Soc Sci Med 2003;57:1429-41.

35 Gaskin DJ, Hoffman C. Racial and ethnic differences in preventable hospitalizations across 10 states. Med Care Res Rev 2000;57(suppl 1): 85-107.

36 O’Neil SS, Lake T, Merrill A, et al. Racial disparities in hospitalizations for ambulatory care-sensitive conditions. Am J Prev Med 2010;38:381-8.

37 Chang CF, Mirvis DM, Waters TM. The effects of race and insurance on potentially avoidable hospitalizations in Tennessee. Med Care Res Rev 2008;65:596-616

38 AHRQ Quality Indicator. National Quality Forum (NQF) endorsed composite and individual measures. 2011. www qualityindicators. ahrq.gov/Downloads/Modules/V43/NQF\%20Endorsed\%20 Composite\%20and\%20Individual\%20Measures.pdf.

39 Methodology for the United States resident population estimates by age, sex, race, and Hispanic origin and the state and county total resident population estimates (Vintage 2011): April 1, 2010 to July 1 , 2011. www.census.gov/popest/methodology/2011-nat-st-co-meth.pdf.

40 Health Resources and Services Administration, US Department of Health and Human Services. Area resource file. National county-level health resource information database. http://arf.hrsa.gov/Population/ ALLVARS list.asp.

41 Health Resources and Services Administration. Health professiona shortage area designation criteria. http://bhpr.hrsa.gov/shortage/ hpsas/designationcriteria/designationcriteria.html.

42 US Census Bureau. Small area health insurance estimates (SAHIE) 2006-2009.

43 Agency for Health Care Research and Quality. Prevention quality indicators technical specifications, version 4.4. www. qualityindicators.ahrq.gov/modules/PQI_TechSpec.aspx.

44 McDonough J, Rosman B, Butt M, et al. Massachusetts health reform implementation: major progress and future challenges. Health Aff (Milwood) 2008:27:w285-97.

45 Hanchate AD, Kapoor A, Katz, JN, et al. Massachusetts health reform and disparities in joint replacement use: difference in differecnes study. BM/2015:350:h440.

46 Chandra A, Holmes J, Skinner J. Is this time different? The slowdown in health care spending. brookings papers on economic activity. Fall 2013:261-302.

47 Woodword M. Epidemiology: study design and data analysis. Chapman and Hall/CRC, 2005

48 Levy H, Meltzer D. The impact of health insurance on health. Annu Rev Publ Health. 2008:29:399-409.

49 Craig P, Cooper C, Gunnell D, et al. Using natural experiments to evaluate population health interventions: new Medical Research Council guidance. J Epidemiol Commun H 2012;66:1182-6.

50 Cameron A, PK T. Microeconometrics: methods and apllications. Cambridge University Press, 2005

51 Wagner AK, Soumerai SB, Zhang F, et al. Segmented regression analysis of interrupted time series studies in medication use research. J Clin Pharm Ther 2002;27:299-309.

52 Rosano A, Abo Loha C, Falvo R, et al. The relationship between avoidable hospitalization and accessibility to primary care: a systematic review. Eur J Public Health 2013:23:356-60.

53 Long S, Stockley K, Yemane A. Another look at the impacts of health reform in Massachusetts:evidence using new data and a stronger model. Am Econ Rev 2009:99:508-11.

54 Truffer CJ, Keehan S, Smith S, et al. Health spending projections through 2019: the recession's impact continues. Health Aff (Milwood) 2010:29:522-9.

55 AHRQ Quality Indicators. Prevention quality indicators overview. Agency for Health Care Research and Quality. www.qualityindicators.
ahrq.gov/Downloads/Modules/PQI/V42/PQI\%20Brochure\%20 10\%20update.pdf.

56 Long SK, Stockley K, Dahlen H. Massachusetts health reforms: uninsurance remains low, self-reported health status improves as state prepares to tackle costs. Health Aff (Milwood) 2012;31:444-51.

57 Keating NL, Kouri EM, He Y, et al. Effect of Massachusetts health insurance reform on mammography use and breast cancer stage at diagnosis. Cancer 2011;41:1-8.

58 Baicker K, Finkelstein A. The effects of Medicaid coverage-learning from the Oregon experiment. N Engl J Med 2011;365:683-85.

59 Finkelstein A, Taubman S, Wright B, et al. The Oregon health insurance experiment: evidence from the first year. Q J Econ 2012;127:1057-106.

60 Miller S. The effect of insurance on emergency room visits: an analysis of the 2006 Massachusetts health reform. J Public Econ 2012;96:893-909.

61 Sommers BD, Baicker K, Epstein AM. Mortality and access to care among adults after state medicaid expansions. N Engl J Med 2012;367:1025-34.

62 Wennberg JE, Staiger DO, Sharp SM, et al. Observational intensity bias associated with illness adjustment: cross sectional analysis of insurance claims. BM/2013;346:5549.

63 Carter GM, Newhouse JP, Relles DA. How much change in the case mix index is DRG creep? J Health Econ 1990;9:411-28.

64 Hall MA. The cost and adequacy of safety net access for the uninsured: Boston, Massachusetts. 2010. www.rwjf.org/files/ research/safetynetmass201006.pdf.

65 McCormick D, Sayah A, Lokko H, et al. Access to care after Massachusetts' health care reform: a safety net hospital patient survey. J Gen Intern Med 2012;27:1584-54.

66 Galbraith AA, Ross-Degnan D, Soumerai SB, et al. Nearly half of families in high-deductible health plans whose members have chronic conditions face substantial financial burden. Health Aff(Milwood) 2011;30:322-31.

67 Massachusetts Medical Society. Physician workforce study. September, 2009. www.massmed.org/AM/Template. $\mathrm{cfm}$ ?Section=Research Reports\%20\%20and Studies2\&TEMPLATE $=/$ CM/ContentDisplay.cfm\&CONTENTID=31511.

68 Kowalczyk L. Across Mass., wait to see doctors grows. Boston Globe www.boston.com/news/health/articles/2008/09/22 across_mass_wait_to_see_doctors_grows/.

69 Joynt KE, Chan D, Orav E), et al. Insurance expansion in Massachusetts did not reduce access among previously insured Medicare patients. Health Aff(Milwood) 2013:32:571-8.

70 Schneider EC, Zaslavsky AM, Epstein AM. Racial disparities in the quality of care for enrollees in medicare managed care. JAMA 2002;287:1288-94.

71 Kressin NR, Petersen LA. Racial differences in the use of invasive cardiovascular procedures: review of the literature and prescription for future research. Ann Intern Med 2001;135:352-66.

72 New California Media (NCM). Bridging language barriers in health care: public opinion survey of California immigrants from Latin America, Asia and the Middle East: the California endowment; 2003.

73 Link CL, McKinlay JB. Only half the problem is being addressed: underinsurance is as big a problem as uninsurance. Int J Health Serv 2010;40:507-23.

74 Smedley BD. Moving beyond access: achieving equity in state health care reform. Health Aff (Milwood) 2008;27:447-55.

75 Buchmueller TC, Grumbach K, Kronick R, et al. The effect of health insurance on medical care utilization and implications for insurance expansion: a review of the literature. Med Care Res Rev 2005;62:3-30.

76 McWilliams J, Meara E, Zaslavsky AM, et al. Health of previously uninsured adults after acquiring medicare coverage. JAMA 2007;298:2886-94.

(C) BMJ Publishing Group Ltd 2015

Appendix 1: Regression models and sensitivity analyses Appendix 2: Supplementary tables A-C 